\title{
CORRELATION BETWEEN PAIN AND MUSCLE STRENGTH IN PATIENTS WITH ADULT SCOLIOSIS
}

\author{
Dimitar Nikolov, Evgeniya Dimitrova \\ Department of Theory and Methods of Physiotherapy, National Sports Academy
}

\begin{abstract}
INTRODUCTION: In this study, we investigate the possible benefits of two different combinations of exercise-based therapies in the treatment of adult idiopathic scoliosis.

MATERIALS AND METHODS: A total of 62 patients (mean age 31.43 years) were selected to participate in the physiotherapy protocol. Pain and trunk muscle strength in patients with scoliosis (mean $10.93^{\circ} \mathrm{Cobb}$ ) were measured in each subject prior to treatment intervention and 6 months following the intervention. The level of pain and trunk muscle strength was analyzed on each test, so pre- and post-comparisons could be made.

RESULTS AND CONCLUSION: After 6 months of treatment, the experimental group averaged a 2.75 reduction in their levels of pain according to the visual analogue scale (VAS), and the control group averaged 1.88 reduction in their levels of pain. None of the patients had an increase of pain. The trunk muscle strength increased in both groups. The combined use of spinal mobilization and postural therapy appeared to significantly reduce the levels of pain and increase trunk muscle strength in all 62 subjects. These results warrant further testing of this protocol.
\end{abstract}

Keywords: adult scoliosis; physiotherapy; idiopathic scoliosis

\section{INTRODUCTION}

The development of scoliosis after the completion of the growth of bony structures has been a subject of various studies. Adult scoliosis is a spinal deformity in a skeletally mature individual, with a curve measuring $>10^{\circ}$ according to the Cobb method. Scoliosis in adults can be further divided into idiopathic and de novo types. Adult idiopathic scoliosis (AIS) refers to a patient with a history of AIS with

Address for correspondence:

Dimitar Nikolov

Department of Theory and Methods of Physiotherapy, NSA

Clinic of Physical Medicine and Rehabilitation

Military Medical Academy

3 Sv. Georgi Sofiyski Str.

1000 Sofia

e-mail:d_s_nikolov@abv.bg

Received: April 24, 2017

Accepted: June 30, 2017 increasing symptoms or progression of the deformity into adulthood. While the main symptom in adolescent scoliosis is deformation, in adult scoliosis it is associated with pain in the spine in $60-80 \%$ of cases (1), neurological symptoms (pinched nerve root of the concave side with irradiated pain), imbalance in the sagittal and coronal plan, which also leads to back pain (2). When a systematic study of the literature (3) on the non-operative treatment of scoliosis after completion of the growth of bone structures was conducted, the authors found only 10 articles in the databases Medline, PubMed, Subscription CINAHL, related to the application of physical therapy in these patients. The relationship between pain and scoliosis (4) is examined. Attention is drawn to the need of further research and quality of life improvement in women with idiopathic scoliosis (5). A number of authors (6-15) recommend a report of the results of a clinically relevant period and number of patients at the beginning and at the end of treatment, 
with the angle of scoliosis over $10^{\circ}$, over $30^{\circ}$ and over $50^{\circ}$ by Cobb. According to them epidemiology recognizes these degrees as risk limits for the possible health effects with increasing age, such as back pain and progression of curvature. In the available literature there is a lack of publications about the relationship between pain and functional capacity in patients of young age with scoliosis, and about the possibilities of kinesitherapy to maintain and improve these indicators.

\section{AIM}

The purpose of this scientific research is to determine the effectiveness of specific kinesitherapeutic exercises that reduce pain and improve muscle strength in patients with adult scoliosis.

\section{MATERIALS AND METHODS}

During the period 2013-2016, the Department of Physical Medicine and Rehabilitation at the Military Medical Academy, Sofia has implemented physical therapy in 62 patients (aged 23 to 44 years) with scoliosis and spinal pain, after completion of the growth of bone structures (Risser 5). The group was dominated by women - 41:21. The angle of curvature varied from $7^{\circ}$ to $18^{\circ}$ and averaged at $10.93^{\circ}$ Cobb. The division of patients into two groups - experimental group - 37 patients at an average age 31.18 years (range, 19-60, S.D. 8.07) and control group - 25 patients at an average age 31.68 years (range, 18-59, S.D. 9.57) was done unintentionally and evenly. The collected data were statistically treated by using SPSS software (Statistical Package for the Social Sciences), version 18.0, SPSS Inc. Chicago, IL, USA, and the following values were found: minimum, maximum, mean, SD, and one sample paired t-test to compare between pre- and post-treatment in results in the group. The unpaired t-test was used to compare preand post-treatment results between two groups, at a confidence level of $\mathrm{P} \leq 0.05$.

The comprehensive rehabilitation program developed by a physician specialist in physical and rehabilitation medicine included:

$\diamond$ Preformed physical factors for pain reduction magnetic therapy, phonophoresis, electrophoresis, interference currents, according to the estimation of the physician regarding the clinical condition of the patient. $\diamond$ Kinesitherapy.

The aim of kinesitherapy in both groups of patients was prevention of the scoliosis progress, pain reduction in the spinal area and improvement of functional abilities.

In the control group (CG) a traditional physical therapy program was executed, including active axial elongation and mobilization of the spine, strengthening the trunk muscles, shoulder muscles, and hip joint muscles, coordination, balance and equilibrium of the body, correction of the posture, breathing and conditional exercises.

In the experimental group (EG), apart from the traditional physical therapy program, there were also added: massage, 3D spine correction exercises, manual mobilization and automobilization of the spine, neurodynamic techniques and manual techniques, and exercises to improve muscle balance.

There were two courses of treatment in 10 procedures over six months. During the rest of the time, the patients were trained to perform a set of exercises to maintain the achieved after the first cycle results 30 minutes a day.

\section{RESULTS AND ANALYSIS}

To evaluate the value of pain we used the visual analogue scale (VAS) where 0 denotes „no pain“ and 10 - „unbearable pain“ (16). The dynamics of the results of the VAS is presented in Fig. 1 and Table 1.

Before treatment, pain in EG was more expressed - 3.16 (SD 1.09) compared to pain in CG 2.72 (SD 0.49) VAS, but the differences were statistically insignificant $(a \geq 0.05)$. At the end of the first rehabilitation course of 10 procedures of physiotherapy (PT) (end 1) a statistically significant reduction of pain in both groups of patients was found (average in EG - 1.46 and 1.72 in CG). During the 6-month individual performance of home PT program pain levels remained at the same level as in the EG and at CG (start 2). At the end of treatment and after the second rehabilitation course (end 2) reduction of pain was significant in both groups of patients $(\alpha \leq 0.001)$, but more expressed in EG $(\Delta X=2.75)$, compared to $C G$ $(\Delta \mathrm{X}=1.88)$. In our view, undoubtedly the preformed physical factors have a positive effect on the reduction of pain in both groups of patients (Table 1). 
Table 1. Variation analysis of data from VAS for pain

\begin{tabular}{lccccccc}
\hline & $\mathrm{EG}$ & $\mathrm{CG}$ & & & & & \\
& average X1 & average X2 & $\Delta \mathrm{X}(\mathrm{X} 1-\mathrm{X} 2)$ & $\mathrm{S} 1$ & $\mathrm{~S} 2$ & $\mathrm{t}$ & $\mathrm{a}$ \\
Beginning & 3.16 & 2.72 & 0.44 & 1.09 & 1.06 & 1.5 & - \\
End & 0.41 & 0.84 & -0.43 & 0.49 & 0.74 & 2.55 & 0.05 \\
$\Delta \mathrm{X}$ & 2.75 & 1.88 & & & & \\
$\mathrm{t}$ & 13.96 & 7.25 & & & & \\
$\mathrm{a}$ & 0.001 & 0.001 & & & & \\
\hline \hline
\end{tabular}

We associate the results from the applied in both groups of patients exercises to activate extension and mobilization of the spine, strengthening the muscles and posture correction as part of the traditional methods of physical therapy (Fig. 1).

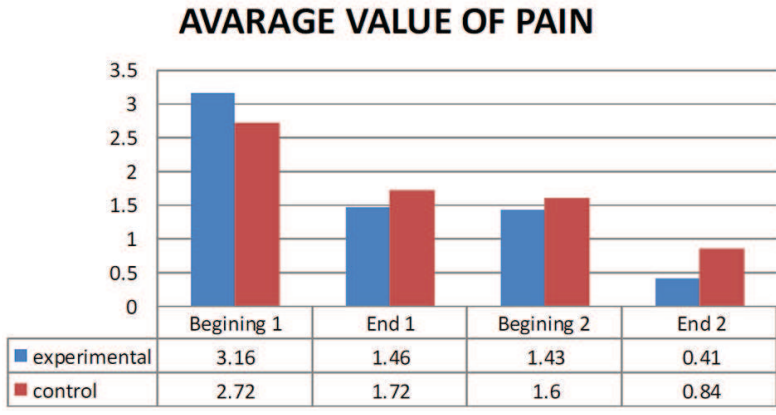

Fig. 1. Results of VAS for pain (average)

The variation analysis of the data at the end of treatment shows statistically significant lower level of pain in EG - an average of 0.41 in the VAS against CG - an average of 0.84 in VAS $(\alpha=0.05)$.

According to us the more expressed possitive change in EG is due to the additionally included in kinesitherapeutic exercise program for active 3D correction of the body's asymmetries, manual mobilization and automobilization of the spine, neurodynamic techniques, exercises and manual techniques for muscle relaxation and balance. Neurodynamic techniques, when applied properly, have a strong effect in reducing the pain and supporting the mobility and mechanical characteristics of the neural structures with prophylactic effect (17).

By reducing pain, the functionality of the respondents significantly improved. We investigated the strength of the trunk muscles by testing static endurance of trunk muscles (18).

Before treatment, a significant proportion of patients in both groups stayed in a test position for abdominal muscles up to 10 seconds because of the pain that inhibits the expression of muscle strength. The allocation of patients in both groups according to this indicator was even and the differences were statistically insignificant.

Comparing data from the final examinations in both groups showed better statistically significant results in EG, compared to CG (Fig. 2).

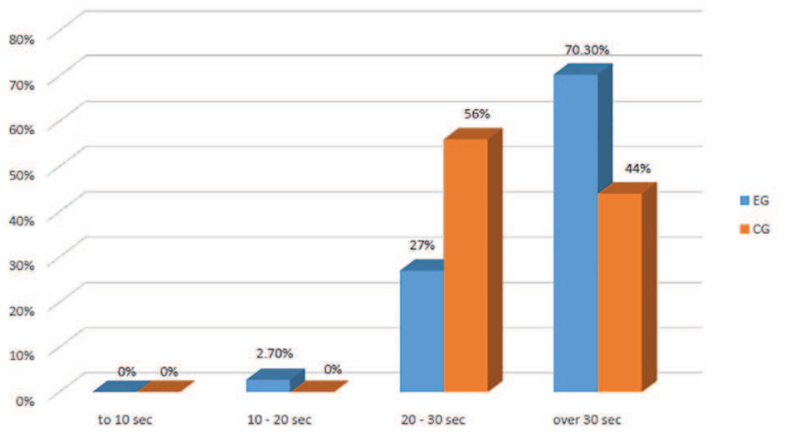

Fig. 2. Comparing outcomes in EG and CG tests for static endurance of abdominal muscles (percentage of patients)

We associated the obtained result with the combination of the traditional method of physical therapy applied in CG of patients, exercises to strengthen the trunk muscles, shoulder and hip muscles and the additionally included in EG exercises and manual techniques to improve muscle balance. Especially effective, we believe, are muscle energy techniques (MET), which are based on methodologies to overcome muscle imbalance $(18,19)$. In our view, compli- 
ance with the indications for the use of MET in cases of muscle imbalance and normalization of activity, tone and elasticity of muscles antagonists create better conditions to stimulate and strengthen the abdominal muscles.

Good static endurance of the abdominal muscles is an important indicator of function as part of the muscle corset, dynamic stabilization of the spine and a prerequisite for good posture.

Testing the lower back muscles was done from prone position with a pillow under the abdomen, hands under chin, elbows sideways. The trunk was fixed between the shoulder blades. The examined raised two lower limbs, stretched horizontally and held them. We measured the holding time for proper testing position in seconds and divided patients according to the achieved result in 5 groups 0-5 seconds, 5-10 seconds, 10-15 seconds, $15-20$ seconds and over $20 \mathrm{sec}$. In the initial measurements the main contingent of EG patients ranged from 5 to 10 seconds - 18 (48.6\%), which was associated with low strength of the lower dorsal muscles. In 10 patients we recorded entirely suppressed by pain strength of the tested muscles, or a total of 28 patients from EG held test position in the range of $0-10$ seconds. In CG the main contingent of patients had better muscle strength - from 10 to 15 seconds - 11 individuals (44\%). CG patients began treatment at a slightly higher level of the functional indicator.

In the majority of patients from both groups the pain did not allow the proper execution of the test at the beginning of treatment.

At the end of the treatment a significantly higher percentage of patients with EG were able to maintain the test position over $20 \mathrm{sec}-14 / 37$ (37.8\%), while the percentage of CG is almost five times lower - 2/25 (8\%). The remaining patients from both groups managed to hold the test position between 10 and $20 \mathrm{sec}-$ onds. The statistical processing of the data shows a significant improvement in static strength endurance of the lower back muscles in both groups of patients when compared to the beginning and approaching normal values $(\mathrm{EG}$ Zemp $=5.324, \mathrm{KG}$ Zemp $=3.755)$. Therefore, the applied physical therapy in both groups led to significant improvement in the strength of the lower dorsal muscles. The comparative analysis of outcomes between the two groups showed statistically significant better results in EG compared to CG (Fig. 3).

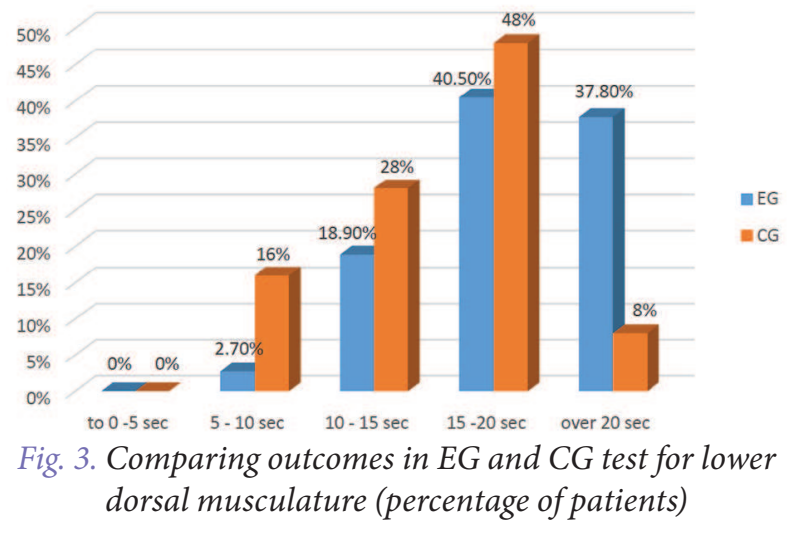

The comparative analysis of the initial and final results of the lateral trunk muscles testing of EG and CG also showed similar dynamics of results and improvement in all patients in both groups. There was no deterioration or retention level of the indicator. Maintaining and improving the capabilities of the muscles of the trunk provided good muscle corset and secondary prevention of complications associated with scoliosis.

By a corelation analysis we explored the relationships between indicators of strength of the abdominal muscles, lower back muscles and the pain. We found significant linear relationships (with significance level ${ }^{\star} \mathrm{P}=95 \%$ and a level of significance $\left.{ }^{*} \mathrm{P}=99 \%\right)$. The indicator strength of the lower back muscles in EG showed increasing correlation of each subsequent measurement of Pearson's correlation coefficients of 0.564 in ${ }^{* *} 0.753^{* *}$ at the start to the end of treatment. This shows the development and strength improvement of lower back muscles during treatment. The relationship between the strength of the lower back muscles and abdominal muscles is preserved in time. There is a low dependence $0.417^{*}$ at the beginning and even lower 0.359 * at the end of treatment. In the CG there was also observed a correlation with the indicator effect of lower back muscles $\left(0.540^{* *}\right.$ at the beginning and $0.684^{* *}$ at end of treatment). At the beginning of the study there was a little correlation to the abdominal musculature 0.400 * and at the end of the period there was no dependence -0.005 . 
Dimitar Nikolov, Evgeniya Dimitrova

During the first course of treatment pain had a strong correlation $0.888^{\star *}$. This shows a very favorable effect during the course. During the 6-month individual practice of healing exercises at home between the two rehabilitation courses there were minor changes of pain $0.714^{* *}$, but the strong correlation was retained. When a second course of treatment was conducted the strong correlation remained, but it was less than in the first course $0.499^{* *}$. This shows favorable development of pain under the influence of the applied by us complex methodology of physical therapy in patients aged over 18 years with scoliosis and pain in the spine. The reduction of pain allows recovery of muscle strength of the trunk muscles.

\section{DISCUSSION}

The functional outcomes gained by us in patients with scoliosis, after completing the growth of the spine, confirm researches by other authors who claim that application of specific kinesitherapeutic exercise in scoliosis affects positively patients, in comparison with natural history of idiopathic scoliosis after 18 years of age (9). Data obtained by us is comparable and better than those described by other authors $(21,22)$ six months after administration of chiropractic rehabilitation and automatic reflex $3 \mathrm{D}$ correction in 28 patients aged over 18 years (1760 years) with a minimum scoliosis of $30^{\circ}$ (average $44^{\circ} \pm 6^{\circ}$ ) by Cobb. Scoliosis in adults is associated with a lower quality of life $(5,23)$, low results from health questionnaire SF-36 $(11,24)$ and prone to development of chronic pain, more often compared to the general population (13). That is why each treatment method that improves the quality of life, applied to our contingent of patients, expands and enriches the kinesitherapeutic practice. Additionally, it is advisable to explore the functional results in a sufficient contingent of patients for an extended period of time.

\section{CONCLUSION}

The administration of physiotherapy in patients with scoliosis after completion of the spine growth results in reduced pain, and restored and maintained strength of the trunk muscles.

The inclusion of specialized therapeutic exercise and manual techniques in the traditional method of physical therapy increases the effectiveness.
The correlation analysis found a significant correlation between the reduction of pain and restoration of the trunk muscles strength.

The application of specific kinesitherapeutic scoliosis exercise reduces the loss of functionality and could be accepted as a possible mean to control the curvature, reduce the pain, and increase the level of functionality and quality of life.

\section{REFERENCES}

1. Daffner S, Vaccaro A. Adult degenerative lumbar scoliosis. Am J Orthop (Belle Mead NJ). 2003; 32(2):77- 82.

2. Glassman SD, Bridwell K, Dimar JR, Horton W, Berven S, Schwab F. The impact of positive sagittal balance in adult spinal deformity. Spine (Phila $\mathrm{Pa}$ 1976). 2005; 30(18):2024-9.

3. Everett CR, Patel RK. A systematic literature review of nonsurgical treatment in adult scoliosis. Spine. 2007;32(9):130-4. doi: 10.1097/ BRS.0b013e318134ea88

4. Weiss HR, Verres C, Lohschmidt K, El Obeidi N. Pain and scoliosis - is there any relationship? Orthop Prax. 1998; 34:602-606.

5. Freidel K, Petermann F, Reichel D, Steiner A, Warschburger P, Weiss HR. Quality of life in women with idiopathic scoliosis. Spine (Phila Pa 1976). 2002; 27(4):87-91.

6. Asher M, Burton D. Adolescent idiopathic scoliosis: natural history and long term treatment effects. Scoliosis. 2006; 1(1):2. doi:10.1186/1748-7161-1-2

7. Hresko MT. Clinical practice: idiopathic scoliosis in adolescents. N Engl J Med. 2013; 368(9):834-41. doi: 10.1056/NEJMcp1209063

8. Mayo NE, Goldberg MS, Poitras B, Scott S, Hanley J. The Ste-Justine adolescent idiopathic scoliosis cohort study. Part III: Back pain. Spine (Phila Pa 1976). 1994; 19(14):1573-81.

9. Negrini A, Negrini MG, Donzelli S, Romano M, Zaina F, Negrini S. Scoliosis-Specific exercises can reduce the progression of severe curves in adult idiopathic scoliosis: a long-term cohort study. Scoliosis. 2015; 10:20. doi: 10.1186/s13013-015-0044-9

10. Negrini S, Aulisa AG, Aulisa L, Circo AB, de Mauroy JC, Durmala J et al. 2011 SOSORT guidelines: orthopaedic and rehabilitation treatment of idiopathic scoliosis during growth. Scoliosis. 2012; 7(1):3. doi: 10.1186/1748-7161-7-3 
11. Negrini S, Grivas TB, Kotwicki T, Maruyama T, Rigo M, Weiss HR. Members of the Scientific society On Scoliosis Orthopaedic and Rehabilitation Treatment (SOSORT): why do we treat adolescent idiopathic scoliosis? What we want to obtain and to avoid for our patients: SOSORT 2005 consensus paper. Scoliosis. 2006;1:4. doi: 10.1186/1748-7161-1-4

12. Weinstein SL, Dolan LA, Cheng JC, Danielsson A, Morcuende JA. Adolescent idiopathic scoliosis. Lancet. 2008; 371(9623):1527-37. doi: 10.1016/ S0140-6736(08)60658-3

13. Weinstein SL, Dolan LA, Spratt KF, Peterson KK, Spoonamore MJ, Ponseti IV. Health and function of patients with untreated idiopathic scoliosis: a 50-year natural history study. JAMA. 2003; 289(5):559-67. doi:10.1001/jama.289.5.559

14. Weinstein SL, Dolan LA, Wright JG, Dobbs MB. Design of the Bracing in Adolescent Idiopathic Scoliosis Trial (BrAIST). Spine (Phila Pa 1976). 2013;38(21):1832-41. doi: 10.1097/01. brs.0000435048.23726.3e

15. Zadeh J, Gleiber M. Adolescent Idiopathic Scoliosis: An in Depth Analysis and Historical Review. MOJ Orthop Rheumatol. 2015; 3(4): 306-34.

16. Aitken R. Measurement of feeling using visual analogue scales. Proc R Soc Med.1969; 62(10): 989 - 93.

17. Dimitrova E. Mobilisation of peripheral nerves. Sofia: NSA PRESS; 2016. 26-29 (in Bulgarian).

18. Karaneshev G, Miltcheva D, Yancheva S. Diagnostics and research in medical gymnastics. Sofia: MF; 1991. 89 (in Bulgarian).

19. Kraydzhikova L. Manual methods of mobilization in musculoskeletal dysfunction in the spine. Sofia: Avangard Prima; 2011. p. 93-96 (in Bulgarian).

20. Chaitow L. Muscle energy techniques. Third ed. Churchill Livingstone; 2006. 6-11.

21. Morningstar M. Outcomes for adult scoliosis patients receiving chiropractic rehabilitation: a 24-month retrospective analysis. J Chiropr Med. 2011; 10(3):179-84. doi: 10.1016/j.jcm.2011.01.006

22. Morningstar M. Scoliosis and ARC3D therapy: restoring hope with non-surgical treatment. Infinity Publishing; 2012. p.86-96.

23. Shapiro GS, Taira G, Boachie-Adjei O. Results of surgical treatment of adult idiopathic scoliosis with low back pain and spinal stenosis: a study of longterm clinical radiographic outcomes. Spine $(\mathrm{Ph}-$ ila Pa 1976). 2003, 28(4):358-63. doi: 10.1097/01. BRS.0000048502.62793.0C

24. Schwab F, Dubey A, Pagala M, Gamez L, Farcy JP. Adult scoliosis: a health assessment analysis by SF36. Spine (Phila Pa 1976) 2003; 28(6):602-6. doi: 10.1097/01.BRS.0000049924.94414.BB 